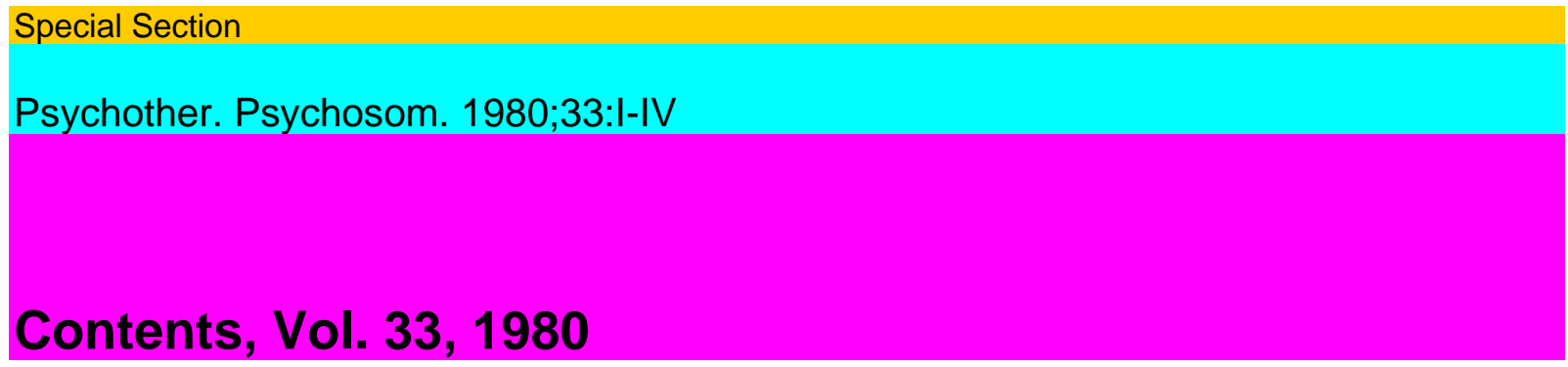

\title{
No. $1-2$
}

Some Experiences of Consultation-Liaison Psychiatry in a University Hospital

Rigatelli, M.; Curci, P., and De Berardinis, M 1

Attributed Responsibility for Life Events in Survivors of Myocardial Infarction

Byrne, D.G 7

Psychiatric Consultation: Compliance and Level of Satisfaction with Recommendations

Van Dyke, C; Rice, D.; Pallett, P., and Leigh, H 14

Schizophrenia Therapy: the Trigger Effect. An Exceptional Response to a Short Inter vention

Lowental, U 25

Methodological Aspects of the Evaluation of Psychotherapies

Leresche, G. and Ballif, J.F 32

Evaluation of Psychotherapies and Osgood's Semantic Differential. A Tentative Ap

proach

Gilliéron, E. and Bovet, J 46

Role of Stereotypes in Selecting Patients for Psychotherapy

Blaser, A.B 59

On the Subject of Handling Hostility in Therapy

Formento, J.J 69

Engagement before Alliance

Nadelson, $\mathrm{T} \quad 76$

Patient Motivation as a Predictor of Process and Outcome in Psychotherapy

Keithly, L.J.; Samples, S.J., and Strupp, H.H 87

Book Reviews 98

Announcements 104

No. 3

Conflictual Maternal Attitudes towards Asthmatic Children

Meijer, A 105

Family Psychiatry in Psychosomatics: Problems of Adolescence

Rubinstein, D 112

Contents IV

Psychosocial Predictors of Cancer and Internal Diseases. An Overview

Grossarth-Maticek, R 122

Social Psychotherapy and Course of the Disease. First Experience with Cancer Patients

Grossarth-Maticek, R 129

On the Measurement of Alexithymic Behavior

Lolas, F.;Parra, G. de la; Aronsohn, S., and Collin, C

Dual Focus in Brief Psychodynamic Psychotherapy

Armstrong, S 147 
Relation of Obsessional Traits to Anxiety in Patients with Ulcerative Colitis

Rabavilas, A.D.; Christodoulou, G.N.iLappas, J.; Perissaki, C, and Stefanis, C. . 155 Different Endocrinal and Hemodynamic Response Patterns to Various Noxious Stimuli

Herrmann, J.M.; Schonecke, O.W.; Wagner, H.; Rosenthal, J., and Schmidt, T.H. . 160 Speech Activity and Respiratory Function in Asthmatics

Mook, J. and Ploeg, H.M. van der 167

Book Reviews 178

No. 4

Münchausen Syndrome. A Review and Two Case Reports

Rimón, R.; Kampman, R.; Ikonen, U., and Reunanen, M 185

Stress and Distress in Essential Hypertension

Osti, R.M.A.;Trombini, G., and Magnani, B 193

Expectation of Death: Case Reports with Implications for Medical and Psychiatric Care

Jensen, G.D 198

A Biobehavioral Model of Obesity

Hartman, L.M 205

Role of Stress in the Development of the Hyperventilation Syndrome

Garssen, B 214

Traumatic Events in Dreams of Psychosomatic Patients

Levitan, H.L 226

Ongoing Outcome Research on Short-Term Dynamic Psychotherapy

Sifneos, P.E.; Apfel, R.J.; Bassuk, E.; Fishman, G., and GUI, A 233

Book Reviews 24?

Author Index 246 